\title{
COVID-19 Impact on RN Nursing Students' Personal \& Professional Lives: A Qualitative Study
}

\author{
Denise Smart*, Sara Welty, Gail Oneal \\ Washington State University, Spokane, WA, USA \\ Email: ^dsmart@wsu.edu
}

How to cite this paper: Smart, D., Welty, S., \& Oneal, G. (2022). COVID-19 Impact on RN Nursing Students' Personal \& Professional Lives: A Qualitative Study. Creative Education, 13, 422-436. https://doi.org/10.4236/ce.2022.132024

Received: November 16, 2021

Accepted: February 11, 2022

Published: February 14, 2022

Copyright ( 2022 by author(s) and Scientific Research Publishing Inc. This work is licensed under the Creative Commons Attribution International License (CC BY 4.0).

http://creativecommons.org/licenses/by/4.0/

\section{(c) (i) Open Access}

\begin{abstract}
This paper explores the experiences early in the pandemic as $\mathrm{RN}$ students added the challenge of pursuing a higher degree with the additional burden of entering into the uncharted territory of a pandemic. Reflexive thematic analysis with an inductive semantic approach was used to analyze $44 \mathrm{RN}$ students' written assignment texts that asked the question: What has been the impact of COVID-9 on your personal and professional lives? Four major themes evolved from the analysis of these reflective papers that explained the trajectory of "being in limbo": Naiveté, Surprise, Challenges Everywhere, and Consequences. These themes revealed what it was like for the RN student participants during the earlier days of the COVID pandemic as found within the context of a disaster preparedness nursing course. Nurse educators have a significant role and obligation to recognize stressors or distress in their students when disasters, significant events or pandemics are in play. Developing intentional curricula strategies for personal and professional resilience through compassionate and supportive learning environments and evidence-based self-care programs is crucial to student retention and early novice career retention.
\end{abstract}

\section{Keywords}

COVID-19, Thematic Analysis, RN Nursing Students, Pandemic, Nurse Retention

\section{Introduction}

Over the decades, the nursing profession has been faced with numerous challenges ranging from nursing shortages (American Association of Colleges of 
Nursing, 2020; Buchan et al., 2015), to nursing identity (Moody et al., 2018) over degree requirements, to the 1980s HIV crisis (Sherman \& Ouellette, 2001), to disasters (VanDevanter et al., 2017), and currently, the COVID-19 pandemic. Neither nurses, health care systems, or the public health infrastructure wanted to be on the "frontlines" and headlines of the news every hour, every day for the past year plus. Yet, the nursing profession has stepped up and faced PPE shortages (Boskoski et al., 2020; Rangachari \& Woods, 2020) with creativity, making personal and family decisions of early retirement, working long hours and often double shifts, receiving furloughs in some cases, and accepting work reassignments to meet the needs of the health care systems that employ them.

Data from the Peterson Center on Healthcare and the Kaiser Family Foundation (Amin \& Cox, 2021) reported that the average cost of hospitalization was $\$ 20,000$ per patient and for a two-month period, the U.S. health care system has incurred approximately $\$ 2.3$ billion in costs for unvaccinated adults. The costs of this pandemic are not just in dollars. With an estimated 3607 heath care workers having died of COVID-19 in the U.S., nurses comprised 32\% of those deaths (Kaiser Health News \& the Guardian, 2021). Nurses and their families have succumbed to significant hardships during the pandemic (Fauteux, 2021). This paper explores the experiences early in the pandemic as RN students added the challenge of pursuing a higher degree with the additional burden of entering into the uncharted territory of a pandemic.

Research illustrates the similarities in pandemic response, particularly with nurses and frontline workers and their responses to traumas experienced. Studies found that nurses experienced increased levels of anxiety and fear directly related to spreading the virus to other patients or family members (Moorthy \& Sankar, 2020), and 38 percent of nursing participants in one study reported new onsets of psychological distress causing depression and post-traumatic stress disorder type symptoms (Lee et al., 2020). Additionally, research shows that even as trauma and stressors increase, nurses are still willing to practice, risking themselves for the good of their patients (Gan et al., 2020).

From the onset of the outbreak, medical professionals expressed concern over the lack of personal protective equipment (PPE), access to resources, and infection control. As patient care and wellbeing is directly related to patient safety, it is evident why PPE concerns would be first and forefront during this pandemic. Researchers found that nurses complaints were centered on a lack of PPE, reuse of single use PPE items, and misinformation from management on conservation or infection control guidelines (Maltby \& Conroy, 2020). In addition to the lack of PPE, studies found that nurses had infection control concerns when using PPE; namely, respondents reported lack of knowledge in the donning and doffing process, the amount of time it takes to respond to patients when fully gowning up, and lack of education regarding the importance of PPE (Gordon \& Thompson, 2020).

During a pandemic response, the physical resource of staffing becomes an is- 
sue; frontline workers can become ill and needing to taking sick leave, or non-essential medical procedures are put on hold indefinitely, resulting in pauses in work or reallocation of skills. Nurses surveyed expressed concern over job reassignments to unfamiliar medical units (Fowler \& Wholeben, 2020), and Halcomb et al. (2020) noted nearly fifty percent of participants reported a reduction in scheduled work hours. As the pandemic moves forward, it becomes evident that resources are required to help nurses adapt. Unfortunately, as the demand for staff increases, the opportunities for education and skills training appear to decrease. Studies have shown that novice nurses report that their lack of experience is a burden for those experienced nurses tasked with training them (Gonzalez \& Garcia-Hernandez, 2021), and that these newer nurses feel that colleagues show little empathy towards them, particularly during times of heightened stress (Petitta et al., 2017). Couple lack of educational opportunities with pandemic response, and novice nurses are left feeling abandoned and incompetent, components for job dissatisfaction and high rates of attrition.

Lastly, the aspect of self-care and wellness during a time of pandemic must be addressed in nursing professionals. Kang et al. (2020) reported that although nearly 80 percent of nursing participants described substantial to moderate mental health concerns directly related to the COVID-19 outbreak and their professional experience, only 36 percent stated utilizing resources or seeking help for self-care and mental wellness. Nurses face incredible stress, emotionally and physically, while working during a pandemic.

Trauma-informed education served as the underlying pedagogy for this disaster preparedness course using the trauma-informed care framework identified by Felitti et al. (1998) and grounded in four assumptions: 1) acknowledging that trauma has widespread impacts; 2) recognizing the signs and symptoms of trauma; 3) responding to trauma through system-wide practices, policies and procedures; and 4) resisting the re-traumatization of individuals. In this study, students were given an assignment to watch self-care videos and then write a narrative response to how COVID-19 is impacting their personal and professional lives and addressing self-care strategies within their control. This assignment gave students a 'voice' to process the impact of the early phase of the pandemic on themselves, their family and their work.

Further studies will be required to identify long term effects related to working under unforeseen and quickly changing circumstances related to the COVID-19 pandemic. Additionally, more research is necessary to identify the work being done for nurses to help create pathways to self-care and wellness, to protect their mental health and wellbeing.

The purpose of this study is to examine the impact of the COVID-19 pandemic on the personal and professional experiences of nursing students through the use of an academic assignment during a disaster preparedness elective course. The research question is: What are the experiences of nursing students doing an assignment related to COVID-19? The aim of this study is to identify the impact 
and factors related to a novel pandemic on students' personal and professional lives.

\section{Methods}

\subsection{Ethics Committee}

This research is a qualitative study reviewed and deemed as exempt by the Institutional Review Board for Washington State University.

\subsection{Data Collection Procedures}

We used a written assignment for the undergraduate disaster preparedness elective course that is taken by both undergraduate and graduate students. This online, asynchronous course explored public health emergency preparedness concepts through written assignments, discussion boards and pre-recorded lectures. Students were emailed notification that one of their assignments was worthy of deeper analysis for this study, that the original objective of the assignment was to identify how COVID-19 impacted their personal and professional lives and what steps were they taking for self-care. Students were given an opportunity to not have their written assignment included in this study. The response from students was that they appreciated the notification, felt that what they shared should be disseminated, and they requested notification should the study be published in the future. The institutional IRB determined that this study was exempt from informed consent since the written papers were de-identified by the PI, the de-identification was completed, and IRB application was submitted after students' final course grades were submitted to reduce any appearance of coercion by the instructor.

\subsection{Population and Setting}

There were 45 students enrolled in the course which comprised nearly $50 \%$ of the entire RN-BSN enrolled students over the 2020 summer. Of the 45 enrolled students, 43 were undergraduate students and 2 were graduate nursing students completing the course for a graduate certificate in public health requirement. This course has been offered every summer for the past eight years with enrollments of 15 - 25. Having an enrollment nearly double the usual size may have been an indication of effects of the COVID-19 pandemic and the students' quest for new knowledge on this public health crisis. Students enrolled in the course live and work throughout two states in the Pacific Northwest with one exception; one participant was moving to the southwest region of the United States.

\subsection{Data Collection}

Data collected were from the reflective written assignment with students telling their stories in $4-5$ pages ( 45 narrative papers). Their writing style ranged from informal to formal $3^{\text {rd }}$ person recounts of how COVID-19 began to impact their lives from March 2020 through July 2020. This early pandemic accounting pro- 
vides the contextual background for the thematic analysis.

\subsection{Data Analysis}

Braun and Clarke's (2006) reflexive thematic analysis with an inductive semantic approach was used to analyze the 45 written assignment texts, following their six steps: 1) familiarizing with the data; 2) generating codes; 3 ) constructing themes; 4) reviewing potential themes; 5) defining and naming themes; and 6) producing the report. A constructivist realist perspective with an empathic approach (Cupchik, 2001) was taken during analysis in which an attempt is made to holistically understand the phenomenon of being a nursing student/nurse as defined by the students during the first months of the COVID-19 pandemic.

The first four texts were read and reread by the research team to become aware of the data, question explanations, develop ideas, and think about responses to the assignment. Each member took notes that were discussed at a team meeting to provide an overall gist of the texts as a dataset and to generate codes. Each team member separately took a number of remaining texts to code by looking for areas of interest and importance related to the research question, using the initial codes from the first set of texts as a guide for similar and new codes. Team meetings were held at several time points for the purpose of discussing the developing codes and possible concepts, and to answer each other's questions about potential codes. The team came together at the end of coding to review, revise, and then organize the codes into related groups for initial theme development as determined by the research question and the purpose for the assignment. To organize the data, a table was made to list each code with its meaning and the text and lines with quotes where it was found. The table was adjusted as codes were organized into related groups, and groups into themes with definitions and meanings. Iterative reflection, review of texts and codes, discussion, and mapping allowed the team to make decisions regarding potential themes, and final themes were identified.

\section{Results}

Of the 45 nursing students enrolled in the course, 13 had recently obtained their Associates Degree in Nursing and their RN licensure at the beginning of the pandemic [March 2020]. These students were now enrolled in an RN-B program as a seamless transition to their academic progression. If one uses Patricia Benner's Novice to Expert concept (Benner, 1982) with novice representing a beginner with no experience and expert as a nurse who no longer needs to rely on principles and rules to associate situations with corresponding nursing actions in clinical settings, then 13 students would be considered novice and 32 would be categorized as expert or at the very least, proficient (see Table 1).

The type of work settings for this group of students ranged from hospitals (n $=29)$ to long term care facilities $(n=6)$ to school nurse settings or pediatric care facilities $(n=3)$ and correctional institutions $(n=2)$. Five participants identified 
Table 1. Participant demographics, experience level \& work settings.

\begin{tabular}{lll}
\hline Gender & Male & $\mathrm{n}=8$ \\
& Females & $\mathrm{n}=37$ \\
Program & Graduate nursing & $\mathrm{n}=2$ \\
& UG nursing & $\mathrm{n}=43$ \\
Experience & Novice & $\mathrm{n}=13$ \\
& Experienced & $\mathrm{n}=32$ \\
Work setting & Acute care/Hospital & $\mathrm{n}=29$ \\
& LTC & $\mathrm{n}=6$ \\
& Schools or pediatric facilities & $\mathrm{n}=3$ \\
& Corrections & $\mathrm{n}=2$ \\
& $*$ COVID-19 designated units & $\mathrm{n}=2$ \\
& Other & $\mathrm{n}=5$ \\
& & $\mathrm{n}=4$ \\
\hline
\end{tabular}

${ }^{\star}$ Counts may overlap in categories.

at some level of leadership or management, one was unemployed, and one was working in a non-RN position awaiting hire in a hospital setting. Four worked on a critical care unit and several had their units converted to COVID-19 care units. Several participants experienced some level of either unemployment, furloughing or reduction in work hours due to surgical and procedure units being closed.

\subsection{Overview of Being in Limbo: The Onset of COVID-19 for Nurses in a Disaster-Preparedness Course}

Participants' stories told in the assignment texts illustrated the state of being in limbo: an uncertain time and place, a midway state where decisions or answers are not forthcoming (Merriam-Webster, n.d.). All described the suddenness of the onset of the COVID-19 pandemic and initially never saw what was coming as a result. They were unprepared and had no other experience to compare to, finding themselves in the unknown with life and work changes, and "left in a limbo state" (C19-13, 1. 18). Every student was impacted but not all in the same ways. Four major themes evolved from the analysis of these reflective papers that explained the trajectory of "being in limbo": Naiveté, Surprise, Challenges Everywhere, and Consequences. These themes revealed what it was like for the student participants during the earlier days of the COVID pandemic as found within the context of a disaster preparedness nursing course.

\subsection{Naiveté}

Naiveté, or being naive, was expressed by most of the participants as simply not knowing what was to unfold; that a new simple virus had been found causing a 
few health concerns but was of no consequence. A participant reflected, as did several others, that "At the start of the pandemic, no one realized the changes that would become...it seemed like it was far from us, and it did not have any impact in the workplace." (C19-03, 1. 2, 8-9). Another participant explained: "I remember listening to many of my co-workers scoff and compare the novel coronavirus to more common viral infections such as the flu or the common cold." (C19-01, 1.14-15). A young woman student, when her mother told her that COVID was discovered in the U.S., wrote; "I shook it off. I didn't think anything of it. At work, of course it was a topic in meetings and a subject for gossip at the nurses' stations." (C19-11, 1. 4-5). As participants indicated, their understanding of the "new" virus came from previous experiences and a feeling of "it couldn't happen here." "A lot of people doubted that it would come to the United States including myself." (C19-02, 1. 3-4). There was initial contempt about all the media attention for the virus by nursing peers or family noted in several papers and observations noting how social media joked "about the correlation to Corona beer." Mostly, participant comments suggested that, initially, the virus would be gone soon and a denial that it would affect them.

\subsection{Surprise}

"It would be safe to state that the Covid-19 pandemic took us all by surprise." (C-19-28, 1. 2). As the pandemic began to unfold in the U.S., naiveté turned to the theme of Surprise. This theme incorporated the new awareness that the virus was more devastating than first thought, impacting everyday life as well as health. Concepts of fear, anxiety, unrealistic expectations, realization of the devastation, and uncertainty were evident in the stories. A number of participants wrote similar statements to this one about the realization of the pandemic: "Not until my daughter's school notified me via text and email that schools would transition to online learning and the announcement of the lock-down did I realize that this was a serious situation." (C-19-23, 1. 8-10). Surprise was not just individually experienced: "As the first American cases of COVID-19 surfaced in King County, so too did the first frisson of fear become apparent among the staff at my hospital. Rumors, speculation, and uncertainty ran rampant." (C19-01, 1. 6-8). Participants who were newer to nursing had expectations that the virus would be over soon and were caught off guard when the numbers of patients grew, as compared to more experienced nurses. One participant shared: “COVID-19 came unexpectedly and it was not something that I prepared for. I started my first nursing job during the COVID-19 pandemic." (C19-25, 1. 5) Another who had graduated in the past year, noted; "I thought it would be years into my practice before I saw this many deaths, and I thought we would have been more prepared or know how to handle these things better." (C19-08, 1. 62-64). Uncertainty reigned and many participants voiced their fears as well as frustrations. "As things in my community began to change, and places were shutting down temporarily, I began to see how real COVID-19 was becoming and the effects 
that were occurring. As rates started to climb in my community, a small amount of worry started to set in. In a very short amount of time, life began to change drastically... I quickly became overwhelmed." (C19-36, 1. 12-23).

\subsection{Challenges Everywhere}

Challenges were everywhere in the lives of the participants and explained the next theme. They were experienced in personal, social, and work dimensions. Chaos was a main concept due to ever-changing or lack of policies and guidelines, being unprepared, not having plans at home to account for any emergency, lack of resources at home and at work, changes in messaging from public health agencies, and from just the "vacuum of knowledge and experience." "To say the environment was chaotic is an understatement. In the beginning of this learning process, the labor pool was on scene to help in any way they could, only they were not given tasks per se to do. We had a ton of help without the roles defined...it was hard to communicate with one another. Not to mention the fear that we all felt. These people were the sickest of the sick. This was just the beginning." (C19-25, 1. 31-35). One participant was particularly overwhelmed when orientation for new nurses was cancelled: "Because of this, starting my first nursing job on March 16th, 2020 [when the state was first shut done], I found that I was walking into literal chaos." (C19-10, 1. 20-21). Constant changes contributed to the feeling of chaos: "March and April passed in a blur of policy changes." (C-19-01, 1. 29).

Effects were seen on the social lives of the student participants. They discussed the fear in family members for the participants' safety and health, as reports of healthcare workers dying became news. Some were requested to stop work. Many participants were unable to see their families for months. There were difficulties managing their children's needs. Some noted the misinformation on social media sites that was contributing to more COVID cases, and more concerning, attacks on nurses in their own communities. "I think one of the biggest challenges is providing education to patients, family, friends, and neighbors regarding how they can be prepared and protect themselves during the pandemic... This is can sometimes be challenging because misinformation regarding COVID-19 is frequently portrayed through social media and can be highly politicized. Additionally, evidence surrounding the virus is frequently changing as the scientific community learns more about the behavior of the virus." (C19-45, 1. 30-38). However, one participant said there was an awaking about the inequity of treatment for certain populations, which was a "learning moment". For some, there was a positive effect as they became aware of the community collaboration that was happening in some communities and they reached out to help.

Economic impacts were felt, as the participants wrote about loss of shifts, their jobs, and/or their partners' jobs. Because of work and to protect their families, they often had to order out for food or goods to be delivered to their homes. To increase family safety, some stayed in rental RVs or motels at work, adding costs 
to their budgets. Overall money issues were considered a big stressor to an already stressful work life.

Participants addressed the challenges of self-care and well-being. For many, self-care was rare, if not impossible. Work fatigue was evident from the number of hours and days that were required and where they worked, often without a choice: "I worked 20 hours days for almost 60 days straight." (C19-34, 1. 39-40.) "We were being assigned to work the front lines whether or not we wanted to." (C19-11, 1. 23-24). Isolation from family and friends brought on feelings of depression and contributed to anxiety and fear. "I have noticed that at times I feel so anxious that I become ill." (C19-2, 1. 35). Many spoke of burnout for themselves and co-workers and of outrage due to no relief.

Yet, others described how they tried to find self-care and well-being in the midst of the challenges from COVID-19. Some saw layoffs as opportunities: " $I$ have used this time to find a new job." (C19-14, 1. 32); "I took this as a blessing and enjoyed all my baby snuggles along with continuing my education... we were able to spend more time with our growing family." (C19-13, 1. 18-21). Others built support networks, as described by one participant; "I have practiced social distancing with friends by utilizing virtual hang-outs over FaceTime video chat. It is not the same but does provide the benefits of socializing since we are seeing each other, having fun, and laughing." (C19-16, 1. 67-61). For another, reflection helped put things into perspective which were echoed by others: "...I thought about how much I wanted to make a difference in the world and here it was, this was my opportunity. So, I began changing things...I am still doing it. While I didn't have time to prepare for a pandemic, now I was in it and doing my best to protect myself and my family while still fulfilling my duty on the front lines." (C19-11, 1. 36-41). Many talked about the support to and from nurse peers to increase well-being, doing things together such as making masks or helping with fundraisers, and especially just being there for each other: "My coworkers and I have laughed and cried together because what can you do sometimes except that?' (C19-17, 1. 55-57).

A strong concern overall was the multiple challenges at work for all the participants. Many noted that employers were not fulfilling their responsibilities and some participants felt that work conditions were unsafe. There were layoffs in some areas of a facility that left other units short of staff. Several participants noted that some nurses were being replaced with nursing assistants who did not have the education for advanced care. Facilities had not planned well, had no disaster plans, and had little to no supplies for impending disasters, especially for personal protective equipment (PPE). In many cases, staff were constantly forced to share or reuse one-time-only PPE and other equipment. In some cases, it was noted there was only one N95 (the standard for COVID) mask for a whole shift. The shortage was known but it was even more upsetting to know that it was happening in the US: "It was horrifying to realize that the global shortage of PPE applied to us as well as the areas hardest hit by the virus." (C19-01, 1. 9-10). 
Yet, even with PPE there were still problems due to organization on units, which left a lasting impact on one participant: "It was highly publicized that we, as a nation, did not have enough PPE gear. So, we were trying to conserve our PPE. During one of my shifts in 'Camp COVID', I was walking by the room of a patient that was not mine and the patient had been recently intubated. As I walked by, I could see the patient was struggling and was starting to reach for their tube instinctively to pull it out. Because this was not my patient, my PPE gear was not outside the room, nor were there any $\mathrm{N} 95 \mathrm{~s}$ for me to quickly put on...nor were there any gowns in the area. I finally found an $N 95$ and gloves and rushed in the room to find the patient foaming at the mouth. I held down the patient's hands and yelled for help. I had been potentially exposed. This patient was younger than me. I went home that night scared. Scared for myself, my family, and my community. I wrote out a will, let my husband know my wishes, and cried myself to sleep." (C19-25, 1. 36-52). Yet, there were also actions that met challenges in the stories. Several participants reshaped care by using Zoom so patients could visit with family. One participant did outreach and developed teams for community support. There were examples of personal leadership by participants such as policing or adapting policies to increase safety, developing better communication processes, and educating all staff, not just healthcare personnel, about airborne precautions and cleaning procedures, but did so not knowing if these actions would be carried forward into the future.

\subsection{Consequences}

As the time of this assignment, COVID-19 had nearly reached the $5^{\text {th }}$ month mark in the US. Participants discussed consequences experienced at this point in relation to being in limbo. While they were starting to get familiar with effects from COVID-19, there were negative and positive consequences occurring and a sense of the unknown leaving them in limbo-would there be an end to COVID? Some discussed the loss of temporary and permanent nursing personnel due to fear, the need to protect themselves and families, or feeling "used" by management in facilities. "At the same time, many of our experienced nurses have opted to leave the hospital due to insufficient hours or stressors at home such as lack of child care, fear of exposing family members, or general caregiver fatigue... we have fewer providers and caregivers available on any given day, patient census is increasing significantly with many high-acuity and resource-intensive patients putting excess strain on the care-giving staff.' (C19-01, 1. 38-45). In fact, one student participant, who recently graduated and received licensure but had not gotten a position, was thinking of changing careers before beginning: "I used to want to be an ICU nurse, specifically CVICU, but when considering the potential for increased exposure to a highly contagious disease, all I can think about are my three young children at home and my fears." (C19-15, 1. 17-19). There were others who contemplated changing roles or workplaces after being in the first wave of COVID. 
Lasting physical and psychological effects were mentioned, including continual long periods of exhaustion and fatigue, early signs of depression, and periods of frustration and anger. One participant noted that, "Everyone needs time to mentally and physically recover, since we still have to work and function as normal as possible." (C19-16, 1. 50-52), which was repeated by others. Looking for strategies to try to stay positive and mentally sound, and in taking ownership of limitations as means to overcoming obstacles was often commented on in many stories, including continuing to lean on peers and others for support. They noted that nurses were getting public support which helped them during tough worktimes, and that roles expanded for some in the workplaces. Hope was mixed with reality in that there was the belief that COVID would eventually be controlled and stopped and that "we are in this together" during that first surge, but that there needed to be changes along with a new normal: "COVID-19 has changed the way we do many things. We have changed our clinical practice, how we treat each patient, and how we communicate with patients." (C19-06, 1. 2). "Overall COVID-19 has taught me to have strength, perseverance, and when to lean into the resources available to my family and me. I am thankful for the opportunities that I have been given and am looking forward to when things return back to normal, whatever that may look like." (C19-39, 1. 59-62).

A main subtheme that presented as a consequence was the recognition that a course could provide support and direction by offering resources embedded in assignments, such as learning how to achieve some measure of self-care, goal making, using a team approach in workplaces, and personal disaster planning, even if there was still a feeling of not knowing when the virus would end. " $B y$ planning, I can minimize the chaos associated with returning to school and work amid COVID-19 constraints." (C19-14, 1. 50-51). More importantly was awareness of their own strengths that was carrying them through: "Nurses are resilient by nature I believe. In order to do our daily jobs, we remain positive and are often looking at situations with critical thinking." (C19-35, 1. 75-77).

In all the stories, they discussed the effects of COVID that had a huge impact on their daily lives, whether at home, school, or work. Because the number of COVID cases had started to reduce, they felt somewhat hopeful, but still were experiencing some anxiety and an uneasiness about what would come next. However, one participant clearly summed up what most others also expressed about what was most important, even though there was still a feeling of being in limbo: "This experience [dealing with COVID] also has served as a good reminder that life is short and it is important to enjoy it because an illness or disaster can jeopardize a life at any moment." (C19-34, 1. 84-85).

\section{Discussion}

Students in this study recognized their own stressors, stress levels and need for self-care strategies. Their early indications of anxiety and fear are corroborated by Rosenthal et al. (2021) where $25 \%$ of 222 graduate nursing students reported 
moderate to severe levels of negative emotional states based on the Depression, Anxiety and Stress Scale and 24\% scored at the level of PTSD on the Impact of Events Scale. In addition, Keener et al. (2020) noted that $21 \%$ - 54\% of the nursing students in their study scored poorly on the quality-of-life domain and recommended the cultivation of resilience, implementing trauma-informed approaches to curriculum and programs, and a need to prepare students for career demands. Students in our study reflected on the impact of community shutdowns on family, relational, work and community engagement. At the time of our study, the students would not have been able to imagine a 1 - 2-year impact on all aspects of life: work, family, academic, and personal. Link et al. (2021) noted in their study similar themes (worry and fear, cyclical stress, mitigation of stress and personal growth) emerging in a cohort of family nurse practitioner students. Their study had similar student sample size $(\mathrm{n}=46)$ and utilized discussion board assignments to capture qualitative data.

Professional socialization which is defined as "forming and internalizing... sameness of professional roles..." (Matsumori \& Kageyama, 2021: p. 828) is one strategy that health care agencies and employers can adopt to bring new nurses into role expectations. This is often translated into residency programs for new nurses which encompasses a formalized preceptor, a structured and extended orientation into the role and unit assigned, and perhaps specialized additional training to meet patient care needs. Professional socialization is part of the process for professional identity and is deemed a crucial component of the novice to expert continuum. During the early weeks of the COVID-19 pandemic, many residency programs were put on pause, hire letters were rescinded, and new RNs hired were assigned to other priority areas. Face-to-face orientations were abandoned and concern for PPE shortages left hospitals, clinics and agencies with other demands and priorities.

Nurse educators have a significant role and obligation to recognize stressors or distress in their students when disasters, significant events or pandemics are in play. Developing intentional curricula strategies such as professional socialization within the boundaries of the academic setting (Matsumori \& Kageyama, 2021; Fitzgerald, 2020) for personal and professional resilience through compassionate and supportive learning environments and evidence-based self-care programs is crucial to student retention and early novice career retention. While not all nursing programs offer disaster preparedness courses, there is generally some content or lessons within a community health curriculum about disaster response, mitigation, and vulnerable populations (Fohrman et al., 2018) which can be applied to students as well. Nursing programs may also have formalized courses or curriculum content designed to address professional identity and socialization which is further supported through employer residency programs. The uncertainty created by COVID-19 will have an impact on how nurses view their roles, the responses and responsibilities of their employers and leadership, and overall, their own level of preparedness in the future as a living lesson. 


\section{Limitations}

Limitations of this study center around a narrow representation of RN nursing students representative of 2 - 3 states within the Pacific Northwest. This was a convenience sample of students enrolled in a disaster/pandemic preparedness course at the beginning of the COVID-19 outbreak. The study was developed retrospectively after reading student written responses and was not originally designed for research intent. The sample did have a mix of novice, mid-career and senior experienced nurses enrolled in either the RN-Baccalaureate (RN-B), the DNP Population Health or the MN Population health program. Many in the RN-B program had recently graduated with the Associate Degree in Nursing and had just passed their NCLEX exams. The course assignment left room for interpretation so did not conform to the usual qualitative interviewing processes, and detailed demographic data were not collected from this sample of 44 students. A follow up study of this same group will be conducted which will capture the time frame subsequent from the early months of the pandemic.

\section{Conclusion}

Despite of the limitations for this study, many personal narratives covered by local and national media and posted on social media appear to reinforce the themes from this qualitative study. The four major themes of naiveté, surprise, challenges everywhere, and consequences reflect the confusion, worry and stress as well as the realization of the need for self-care, employer and faculty support, and for educators to practice trauma-informed pedagogy in the classroom and clinical settings.

\section{Conflicts of Interest}

The authors declare no conflicts of interest regarding the publication of this paper.

\section{References}

American Association of Colleges of Nursing (2020). Fact Sheet: Nursing Shortage. https://www.aacnnursing.org/Portals/42/News/Factsheets/Nursing-Shortage-Factsheet. pdf

Amin, K., \& Cox, C. (2021). Unvaccinated COVID-19 Hospitalization Costs the U.S. Health System Billions of Dollars. Peterson Center on Healthcare \& Kaiser Family Foundation Health Spending Briefs.

https://www.healthsystemtracker.org/brief/unvaccinated-covid-patients-cost-the-u-s-h ealth-system-billions-of-dollars/

Benner, P. (1982). From Novice to Expert. American Journal of Nursing, 82, 402-407. https://doi.org/10.1097/00000446-198282030-00004

Boskoski, I., Gallo, C., Wallace, M., \& Costamagna, G. (2020). COVID-19 Pandemic and Personal Protective Equipment Shortage: Protective Efficacy Comparing Masks and Scientific Methods for Respirator Reuse. Gastrointestinal Endoscopy, 92, 519-523.

Braun, V., \& Clark, V. (2006). Using Thematic Analysis in Psychology. Qualitative Re- 
search in Psychology, 3, 77-101. https://doi.org/10.1191/1478088706qp063oa

Buchan, J., Duffield, C., \& Jordan, A. (2015). 'Solving' Nursing Shortages: Do We Need a New Agenda? Journal of Nursing Management, 23, 543-545. https://doi.org/10.1111/jonm.12315

Cupchik, G. (2001). Constructivist Realism: An Onotology that Encompasses Positivist and Constructivist Approaches to the Social Sciences. Forum Qualitative Sozialforschung/Forum: Qualitative Social Research, 2, Article No. 7. https://doi.org/10.17169/fqs-2.1.968

Fauteux, N. (2021). COVID-19: Impact on Nurses and Nursing. American Journal of Nursing, 121, 19-21. https://doi.org/10.1097/01.NAJ.0000751076.87046.19

Felitti, V. J., Anda, R. F., Nordenberg, D., Williamson, D. F., Spitz, A. M., Edwards, V., \& Marks, J. S. (1998). Relationship of Childhood Abuse and Household Dysfunction to Many of the Leading Causes of Death in Adults: The Adverse Childhood Experiences (ACE) Study. American Journal of Preventive Medicine, 14, 245-258. Https://doi.org/10.1016/s0749-3797(98)00017-8

Fitzgerald, A. (2020). Professional Identify: A Concept Analysis. Nursing Forum, 55, 447-472. https://doi.org/10.1111/nuf.12450

Fohrman, J., Jabbouri, S., Winters, H., Pahang, J., George, A., Smart, D., \& Akins, R. (2018). The Role of Public Health Nurses in Bioterrorism Preparedness-13 Years Later. Internal Medicine Review, 4, 1-24.

Fowler, K., \& Wholeben, M. (2020). COVID-19: Outcomes for Trauma-Impacted Nurses and Nursing Students. Nurse Education Today, 93, Article ID: 104525. https://doi.org/10.1016/j.nedt.2020.104525

Gan, X. Q., Shi, Z. Y., Chair, S. Y., Cao, X., \& Wang, Q. (2020). Willingness of Chinese Nurses to Practice in Hubei Combating the Coronavirus Disease 2019 Epidemic: A Cross-Sectional Study. Journal of Advanced Nursing, 76, 2137-2150.

Gonzalez, C. M., \& Garcia-Hernandez, A. M. (2021). What Services, or Work Units, Do Nurses Experience in a More Traumatic Way When Entering the Professional World in Tenerife, Spain? A Phenomenological Study. Journal of Organizational Psychology, 21, No. 2. https://doi.org/10.33423/jop.v21i2.4201

Gordon, C., \& Thompson, A. (2020). Supply and Demand of PPE. British Journal of Nursing (Mark Allen Publishing), 29, 592.

https://doi.org/10.12968/bjon.2020.29.11.592

Halcomb, E., McInnes, S., Williams, A., Ashley, C., James, S., Fernandez, R., Stephen, C., \& Calma, K. (2020). The Experiences of Primary Healthcare Nurses during the COVID-19 Pandemic in Australia. Journal of Nursing Scholarship, 52, 553-563. https://doi.org/10.1111/jnu.12589

Kaiser Health News \& the Guardian (2021). Lost on the Front Line Database. https://www.theguardian.com/us-news/series/lost-on-the-frontline

Kang, L., Ma, S., Chen, M., Yang, J., Wang, Y., Li, R., Yao, L., Bai, H., Cai, Z., Xiang Yang, B., Hu, S., Zhang, K., Wang, G., Ma, C., \& Liu, Z. (2020). Impact on Mental Health and Perceptions of Psychological Care among Medical and Nursing Staff in Wuhan during the 2019 Novel Coronavirus Disease Outbreak: A Cross-Sectional Study. Brain, Behavior, and Immunity, 87, 11-17. https://doi.org/10.1016/j.bbi.2020.03.028

Keener, T., Hall, K., Wang. K., Hulsey, T., \& Piamjariyakul, U. (2020). Quality of Life, Resilience, \& Related-Factors of Nursing Students during the COVID-19 Pandemic. Nurse Educator, 46, 143-148. https://doi.org/10.1097/NNE.0000000000000969

Lee, M. C. C., Thampi, S., Chan, H. P., Khoo, D., Chin, B. Z. B., Foo, D. P. X., Lua, C. B., 
Lewin, B., \& Jacob, R. (2020). Psychological Distress during the COVID-19 Pandemic amongst Anaesthesiologists and Nurses. BJA: The British Journal of Anaesthesia, 125, e384-e386.

Link, T., Laham, K., Hubbell, S., \& Baisden, P. (2021). Reflections of Family Nurse Practitioner Students during the COVID-19 Pandemic: A Qualitative Study. Journal of Nursing Education, 60, 449-452. https://doi.org/10.3928/01484834-20210722-06

Maltby, H., \& Conroy, C. (2020). Coalition of Vermont Nurse and Nurse Practitioner Leaders Responds to the ANA-VT Survey on COVID-19: Themes and Recommendations. Vermont Nurse Connection, 23, 7.

Matsumori, N. \& Kageyama, Y. (2021). Literature Review of Nursing Education Promoting Professional Socialization among Nursing Students. Open Journal of Nursing, 11, 828-846. https://doi.org/10.4236/ojn.2021.1110069

Merriam-Webster (n.d.). Limbo. Merrian-Webster.com. https://www.merriam-webster.com/dictionary/limbo

Moody, L., Teel, C., \& Peltzer, J. (2018). Advancing Nursing Education: BSN Completion Messaging Materials for Associate Degree Program Nursing Faculty. Nursing Education Perspectives, 39, E21-E25. https://doi.org/10.1097/01.NEP.0000000000000342

Moorthy, A., \& Sankar, T. K. (2020). Emerging Public Health Challenge in UK: Perception and Belief on Increased COVID19 Death among BAME Healthcare Workers. Journal of Public Health, 42, 486-492. https://doi.org/10.1093/pubmed/fdaa096

Petitta, L., Jiang, L., \& Hartel, C. E. J. (2017). Emotional Contagion \& Burnout among Nurse and Doctors: Do Joy and Anger from Different Sources of Stakeholders Matter? Stress and Health, 33, 358-369. https://doi.org/10.1002/smi.2724

Rangachari, P., \& Woods, J. L. (2020). Preserving Organizational Resilience, Patient Safety, and Staff Retention during COVID-19 Requires a Holistic Consideration of the Psychological Safety of Healthcare Workers. International Journal of Environmental Research \& Public Health, 17, Article No. 4267. https://doi.org/10.3390/ijerph17124267

Rosenthal, L., Lee, S., Jenkins, P., Arbet, J., Carrington, S., Hoon, S., Purcell, S. K., \& Nodine, P. (2021). A Survey of Mental Health in Graduate Nursing Students during the COVID-19 Pandemic. Nurse Educator, 46, 215-220. https://doi.org/10.1097/NNE.0000000000001013

Sherman, D. W., \& Ouellette, S. C. (2001). Patients Tell of Their Images, Expectations, and Experiences with Physicians and Nurses on an AIDS-Designated Unit. Journal of the Association of Nurses in AIDS Care, 12, 84-94.

VanDevanter, N., Raveis, V., Kovner, C., McCollum, M., \& Keller, R. (2017). Challenges and Resources for Nurses Participating in a Hurricane Sandy Hospital Evacuation. Journal of Nursing Scholarship, 49, 635-643. https://doi.org/10.1111/jnu.12329 